\title{
Can robot-assisted mitral repairs be super good?
}

\author{
W. Randolph Chitwood, Jr, MD, FACS, FRCS
}

From the Department of Cardiovascular Sciences, Brody School of Medicine, East Carolina University, Green-
ville, NC.
Disclosures: Author has nothing to disclose with regard to commercial support.
Received for publication Sept 8, 2017; accepted for publication Sept 9, 2017; available ahead of print Oct 6, 2017.
Address for reprints: W. Randolph Chitwood, Jr, MD, FACS, FRCS, 146 E Longmeadow Rd, Greenville, NC
27858 (E-mail: chitwoodw@ ecu.edu).
J Thorac Cardiovasc Surg 2018;155:94-5
0022-5223/\$36.00
Copyright @ 2017 by The American Association for Thoracic Surgery
https://doi.org/10.1016/j.jtcvs.2017.09.042

Carpentier and Mohr performed the first robot-assisted mitral repairs operations in 1998, with a prototype da Vinci surgical system (Intuitive Surgical, Inc, Sunnyvale, Calif). In May 2000, we performed the first da Vinci repair in the United States under a US Food and Drug Administration safety and efficacy clinical trial. Thereafter, we trained teams from several large referral centers, who began to perform robot-assisted mitral repairs routinely. Despite their early successes, robotic mitral valve surgery evolved slowly during the intervening years.

The Cleveland Clinic was the first large referral center to begin robot-assisted mitral repairs. In this issue of the Journal, Gillinov and colleagues ${ }^{1}$ report their first 1000 mitral operations (992 repairs) with the da Vinci surgical robot. This article focuses on ways to achieve procedural success, effectiveness, and patient safety in robot-assisted mitral valve surgery. Their operative results were comparable to, if not better than, many reported sternotomy-access repair series.

With experience, most surgical series show decreasing operative times, with improved results and fewer complications. Gillinov and colleagues, ${ }^{1}$ however, describe other key elements that affected improvements during their robotic mitral surgery journey. To be sure, expertise, experience, and clinical volume were very important. This article also shows, however, that careful patient selection was important in decreasing complications. To ensure the best outcomes and safety, they used a screening algorithm in most cases. In this operative setting, strokes usually result from embolic debris related to retrograde perfusion, endoballoon passage, or direct aortic clamping. Peripheral perfusion was used in all 1000 patients, and aortic occlusion varied between endoballoon and transthoracic direct clamping. In their first 500 patients, computed tomographic scanning was not used routinely, and the stroke rate was $2 \%$. After they implemented routine computed tomographic scanning in the second 500 patients, the stroke rate fell to $0.8 \%$. This suggests that vascular screening can be protective for patients who will require peripheral perfusion and either aortic occlusion method. According to this algorithm, they also deferred patients with aortic

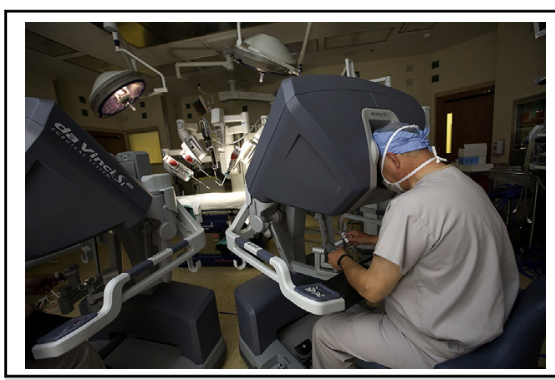

The da Vinci robot! Great vision, ergonomics, surgeon comfort for mitral valve surgery.

Central Message

Gillinov et al report their first 1000 robotassisted mitral operations, done safely and effectively. Their screening algorithm should help other surgeons select patients for best outcomes and safety.

See Article page 82.

insufficiency, severe pulmonary hypertension, annular calcification, and poor ventricular function for more traditional operations.

Their excellent results also relate to other factors that may have been discovered in their screening process. Intervening factors include a mean patient age of 56 years, with few patients having either atrial fibrillation or tricuspid regurgitation and most having only posterior leaflet pathology. In my personal series of 940 robot-assisted mitral operations, patients had more comorbidities (eg, $13 \%$ with ejection fraction $<45 \%$ ) and operative complexities (eg, 34\% undergoing maze operations for atrial fibrillation). Moreover, computed tomographic screening was done infrequently. The overall stroke and reoperative rates were $1.3 \%$ (greater in the cohort undergoing maze operations for atrial fibrillation) and $2.5 \%$, respectively. ${ }^{2,3}$ In retrospect, it seems that application of the screening algorithm of Gillinov and colleagues $^{1}$ could have avoided complications and reoperations. This article thus sets a new standard for patient evaluation in robot-assisted repair candidates.

Today "personalized" is the watchword in medicine and surgery-and this holds true for mitral repair surgery. Careful patient selection, combined with customized surgery, is the best way to gain optimal outcomes. In this article, Gillinov and colleagues ${ }^{1}$ emphasize that robot assistance can provide the least-invasive mitral valve repair with excellent outcomes in carefully screened patients. In 
the right surgeon's hands in selected patients, robot-assisted mitral repairs can be super good.

\section{References}

1. Gillinov MA, Mihaljevic T, Javadikasgari H, Suri RM, Mick SL, Navia JL, et al. Early results of robotically assisted mitral valve surgery: analysis of the first 1000 cases. J Thorac Cardiovasc Surg. 2018;155: 82-91.e2.

2. Nifong LW, Rodriguez E, Chitwood WR Jr. 540 consecutive robotic mitral valve repairs including concomitant atrial fibrillation cryoablation. Ann Thorac Surg. 2012;94:38-42; discussion 43

3. Chitwood WR Jr. Robotic mitral valve surgery: overview, methodology, results, and perspective. Ann Cardiothorac Surg. 2016;5:544-55. 